\title{
Characterization of novel W alloys produced by HIP
}

\author{
M.A. Monge ${ }^{\mathrm{a}, *}$, M.A. Auger $^{\mathrm{a}}$, T. Leguey $^{\mathrm{a}}$, Y. Ortega $^{\mathrm{a}}$, L. Bolzoni ${ }^{\mathrm{b}}$, E. Gordo $^{\mathrm{b}}$, R. Pareja $^{\mathrm{a}}$ \\ ${ }^{a}$ Departamento de Física, Universidad Carlos III de Madrid, 28911 Leganés, Spain \\ ${ }^{\mathrm{b}}$ Departamento de Ciencias de Materiales, Universidad Carlos III de Madrid, 28911 Leganés, Spain
}

\begin{abstract}
W}$ and $\mathrm{W}$ alloys containing $0.5 \mathrm{wt} \% \mathrm{Y}_{2} \mathrm{O}_{3}, x$ wt $\% \mathrm{Ti}$ and $\left(x \mathrm{wt} \% \mathrm{Ti}+0.5 \mathrm{wt} \% \mathrm{Y}_{2} \mathrm{O}_{3}\right)$ have been prepared, $x \quad 2$ or 4 . Elemental powders were blended or ball milled, canned, degassed and finally consolidated by a two stage HIP process under a pressure of $195 \mathrm{MPa}$. It is found that Ti addition favours the densification attaining a fully dense material. XRD, SEM and EDX analyses of the material with Ti addition reveal the formation of a microstructure consisting of tungsten particles embedded in a W Ti matrix. The microhardness of these materials increased noticeably with the titanium content.
\end{abstract}

\section{Introduction}

$\mathrm{W}$ is considered as a candidate material for plasma facing com ponents (PFCs) in a future fusion power reactor because of its refrac tory characteristics, low tritium retention and low sputtering yielding [1,2]. However, its use in PFCs requires the development of $\mathrm{W}$ alloys that, in addition to these properties, maintain good mechanical properties after a prolonged exposure at high tempera ture. Sintering would be the most suitable method to produce $\mathrm{W}$ materials for these applications if their recrystallization tempera ture is high enough and the grain growth is restrained. The usual sin tering conditions for $\mathrm{W}$ require very high temperatures that induce a coarse grained structure in the sintered material, and a low recrys tallization temperature in the hot worked material. This causes the failure of its mechanical properties. The combined addition of a sintering activator, which lowers the sintering temperature and fa vours the densification, and an insoluble oxide that produces a dis persion strengthening and grain growth inhibition, may result in a W material with improved mechanical characteristics.

Moreover, oxide dispersed $\mathrm{W}$ alloys have been envisaged as po tential structural materials for a modular He cooled divertor of the fusion demonstration reactor DEMO [1]. In particular, conceptual designs based on sintered $\mathrm{W}$ tiles joined to a $\mathrm{W} \mathrm{La}_{2} \mathrm{O}_{3}$ thimble structure are being considered $[3,4]$. In the case of developing a W alloy suitable for PFCs, a critical issue would be the joining be tween different $\mathrm{W}$ material components. Joining experiments per formed on sintered $\mathrm{W} / \mathrm{W} \mathrm{La}_{2} \mathrm{O}_{3}$ have demonstrated the feasibility of the joint if a Ti interlayer is used [3]. These results suggest that $\mathrm{W} / \mathrm{W}$ Ti would be more effectively joined than $\mathrm{W} / \mathrm{W} \mathrm{La}_{2} \mathrm{O}_{3}$. Then,

\footnotetext{
* Corresponding author. Tel.: +34 9162494 14; fax: +34 91624 8749. Email address: mmonge@fis.uc3m.es (M.A. Monge).
}

oxide dispersed W Ti alloys appear to be promising materials for the fabrication of divertor components.

The present work assesses the possibility of using jointly $\mathrm{Ti}$ as sintering activator and $\mathrm{Y}_{2} \mathrm{O}_{3}$ particles as strengthening dispersoids in $\mathrm{W}$.

\section{Experimental}

The starting materials were $99.9 \%$ pure $\mathrm{W}$ and $99.8 \%$ pure $\alpha \mathrm{Ti}$ powders with an average particle size of 14 and $20 \mu \mathrm{m}$, respec tively, and $99.5 \%$ pure nanometric $\mathrm{Y}_{2} \mathrm{O}_{3}$ powder with particle sizes between 10 and $50 \mathrm{~nm}$. Powder blends with compositions W 4 wt\% Ti were prepared mixing together the powder inside a container sealed under a high purity $\mathrm{Ar}$ atmosphere. Blends with compositions $\mathrm{W} 0.5 \mathrm{wt} \% \mathrm{Y}_{2} \mathrm{O}_{3}, \mathrm{~W} 4 \mathrm{wt} \%$ Ti $0.50 \mathrm{wt} \% \mathrm{Y}_{2} \mathrm{O}_{3}$ and $\mathrm{W} 2 \mathrm{wt} \% \mathrm{Ti} 0.47 \mathrm{wt} \% \mathrm{Y}_{2} \mathrm{O}_{3}$ were mixed by high energy milling for $2 \mathrm{~h}$ in a planetary mill under a high purity $\mathrm{Ar}$ atmosphere. In this case, a WC container and WC balls of $\varnothing 10 \mathrm{~mm}$, as grinding media, were used. The blends were canned and degassed at $673 \mathrm{~K}$ for $24 \mathrm{~h}$ in vacuum and then the can sealed. First, the cans were HIP treated at $1550 \mathrm{~K}$ for $2 \mathrm{~h}$ at a pressure of $195 \mathrm{MPa}$. After removing the can, the consolidated billet underwent a second HIP at $1973 \mathrm{~K}$ for $30 \mathrm{~min}$ in a pure $\mathrm{Ar}$ atmosphere at $195 \mathrm{MPa}$.

The microstructural characteristics were investigated using light microscopy, scanning electron microscopy (SEM) and energy dispersive $\mathrm{X}$ ray (EDX) analyses. Moreover, $\mathrm{X}$ ray diffraction (XRD) analyses were made. Vickers microhardness measurements were performed applying a load of $2.94 \mathrm{~N}$ during $20 \mathrm{~s}$. Transmission electron microscopy (TEM) observations and EDX analyses were performed on ion milled samples in a Philips Tecnai microscope at $200 \mathrm{kV}$. The ion milling conditions were $\theta=6, V=7 \mathrm{kV}$ and $I=2.6 \mathrm{~mA}$. 


\section{Results and discussion}

\section{1. $W$ and $W 0.50 Y_{2} O_{3}$}

After the first HIP at $1550 \mathrm{~K}$ the consolidated $\mathrm{W}$ material re sulted in a relative density of $92.7 \%$. The second HIP at $1973 \mathrm{~K}$ pro duced no meaningful increase in the density. Fig. $1 \mathrm{a}$ and $\mathrm{b}$ show the microstructure of the $\mathrm{W}$ material after the second HIP stage. A strong pore shrinkage and formation of high angle grain boundaries induced by coalescence of the tungsten particles were observed. The mean grain size $D_{50}$ for $\mathrm{W}$ was $\sim 4.4 \mu \mathrm{m}$ after the second HIP at 1973 K.

The microstructure of the $\mathrm{W} 0.50 \mathrm{Y}_{2} \mathrm{O}_{3}$ material HIP treated at $1550 \mathrm{~K}$ was similar to that corresponding to W. Pores appear mainly formed at triple or quadruple junctions between the $\mathrm{W}$ grains, see Fig. 2a. The relative density and the mean grain size measured after the first HIP treatment result in $\sim 90 \%$ and $\sim 4.0 \mu \mathrm{m}$, respectively. EDX analyses showed no evidence of $\mathrm{Y}$ and $\mathrm{O}$ on the sample surfaces. Despite of the open porosity, esti mated in $\sim 8 \%$ from metallographic analyses, the porosity of this material decreased after the second HIP treatment. Fig. 2b and c show micrographs of W $0.50 \mathrm{Y}_{2} \mathrm{O}_{3}$ after the second HIP treatment at 1973 K. SEM EDX analyses revealed the presence of a new phase containing $\mathrm{Y}$ and $\mathrm{O}$ in the residual marks of previous pores like areas 1 and 2 in Fig. 2b and c. Fig. 2c shows the appearance of grains of these oxides surrounding a $\mathrm{W}$ particle; the average com position of these grains correspond to 51 at.\% O, 21 at.\% W and 18 at.\% Y. The mean size of the oxide grains was estimated in $0.62 \mu \mathrm{m}$.
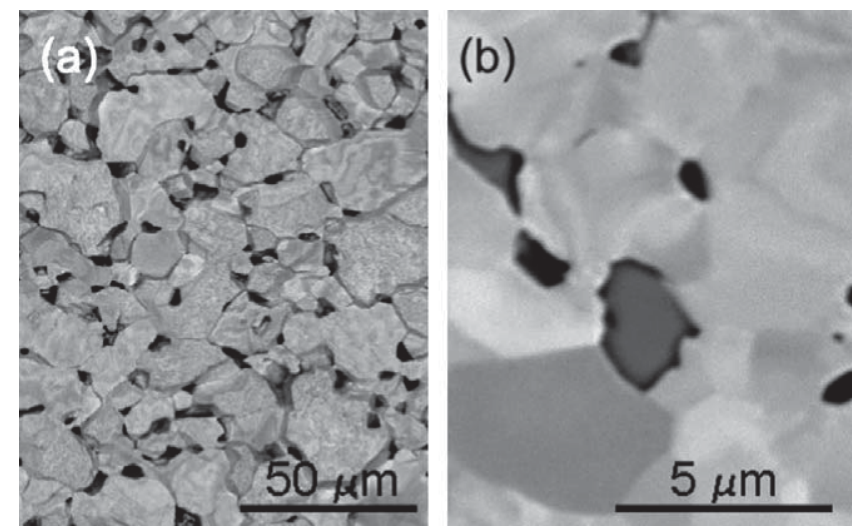

Fig. 1. SE-SEM micrographs of $\mathrm{W}$ consolidated by HIP after $30 \mathrm{~min}$ at $1973 \mathrm{~K}$ and $195 \mathrm{MPa}(\mathrm{a})$ and (b) etched with Murakami reagent.
The new ( $\left.\begin{array}{ll}\mathrm{W} & \mathrm{Y}\end{array}\right)$ oxide phase filled most of the pores present after the first HIP treatment stage. This evidences the pore shrink age by segregation of the new phase, and it may be the main cause of the apparent densification of the alloy. The relative density can not be accurately determined because of the appearance of this new phase. However, from metallographic analyses the volume fraction of this phase was estimated in $\sim 3.8 \%$ and the porosity in $\sim 0.2 \%$.

The TEM observations performed on $\mathrm{W} 0.5 \mathrm{Y}_{2} \mathrm{O}_{3}$ after the second HIP treatment showed tungsten grains with typical sizes between 2 and $5 \mu \mathrm{m}$. These sizes might not be representative of the characteristic grain size of the sample because only small areas of sample were transparent to the electron beam. These tungsten grains and their boundaries were free of second phase precipitates and the EDX analyses did not detected presence of impurities. Moreover, they were apparently dislocation free. In some visible areas of these $\mathrm{W} 0.5 \mathrm{Y}_{2} \mathrm{O}_{3}$ samples, small grains of phases contain ing $\mathrm{O}, \mathrm{Y}, \mathrm{W}, \mathrm{Cr}$ and $\mathrm{Ti}$ appeared alongside of the tungsten grains, as Fig. 3 shows. These grains, which had sizes $<1 \mu \mathrm{m}$, exhibited differ ent composition and crystallographic structure from each other. The analyses revealed that the grains were complex oxides con taining $\mathrm{Y}$ and $\mathrm{W}$, and unwanted $\mathrm{Cr}$ and $\mathrm{Ti}$ impurities. These impu rities might be either concomitant impurities of the starting powders or contamination from the pot and grinding media. The

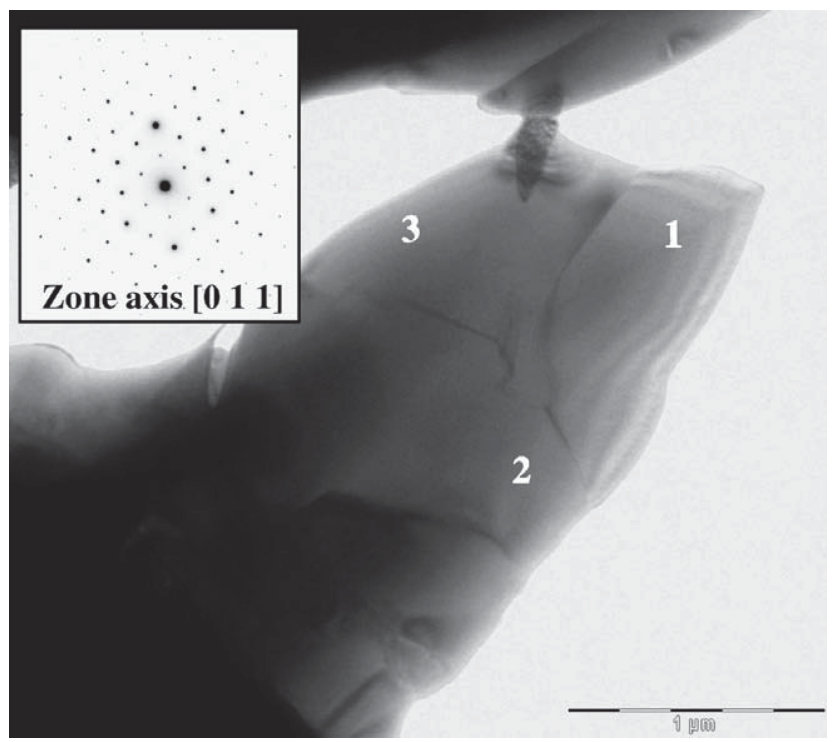

Fig. 3. TEM image showing the complex oxides formed alongside of the $\mathrm{W}$ grains in $\mathrm{W}-0.5 \mathrm{Y}_{2} \mathrm{O}_{3}$ samples after the second HIP treatment at $1973 \mathrm{~K}$. The SAD pattern with zone axis [011] to corresponds grain 1.
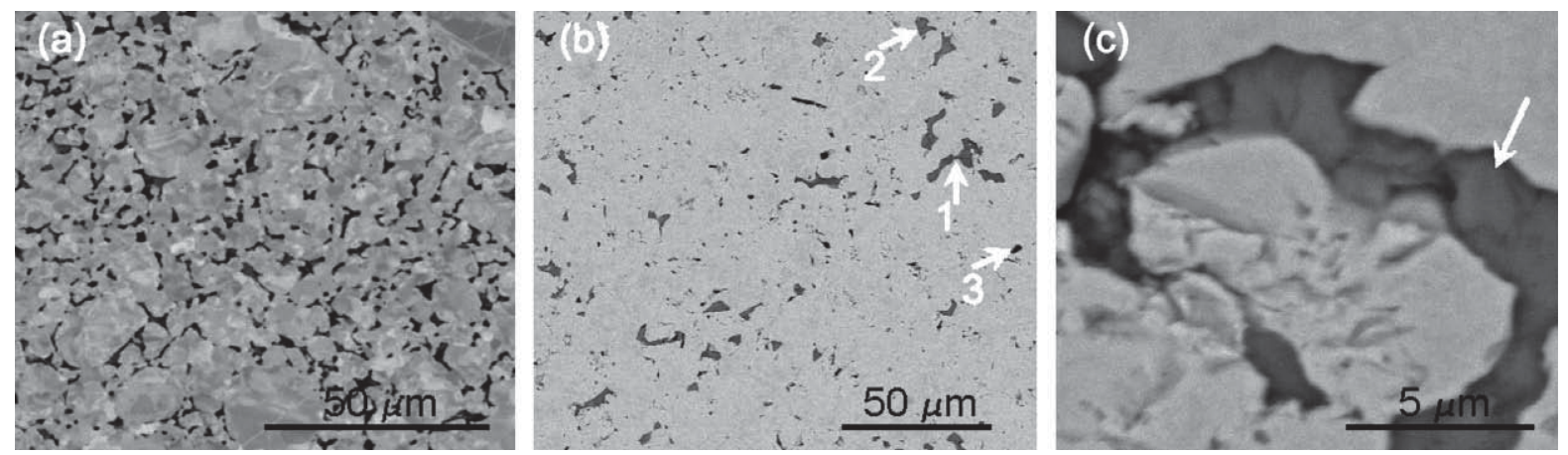

Fig. 2. BSE-SEM micrographs of W- $0.5 \mathrm{Y}_{2} \mathrm{O}_{3}$ after HIP consolidation: (a) $2 \mathrm{~h}$ at $1550 \mathrm{~K}$ and $195 \mathrm{MPa}$, (b) and (c) after second $\mathrm{HIP}$ for $30 \mathrm{~min}$ at $1973 \mathrm{~K}$ and $195 \mathrm{MPa}$. The samples have not been etched to avoid the preferential etching of the new ( $\mathrm{W}-\mathrm{Y}$ ) oxide phase (dark grey contrast) in areas 1 and 2 of (b), and white arrow (c). 
identification of these oxides from the selected area diffraction pat terns (SAD) is difficult because agreement with the lattice param eters reported for $\mathrm{Y}$ W oxides have not found. For instance, the grain denoted by 1 in Fig. 3 is identified from the SAD patterns as an fcc crystal with a lattice parameter of $0.989 \pm 0.005 \mathrm{~nm}$. TEM analyses are still in progress to identify these complex oxide phases.

\subsection{W 4Ti alloy}

The W 4Ti material obtained after the first HIP treatment re sulted in a density of $17.09 \pm 0.05 \mathrm{~g} / \mathrm{cm}^{3}$ in agreement to the theo retical value. After the first HIP treatment practically the whole content of $\mathrm{Ti}$ appears as $\beta \mathrm{Ti}$, only a meaningless residual signal from $\alpha$ Ti was detected. The analyses of the patterns using the program Fullproof suggest that the observed peaks could be the convolution of two peaks corresponding to two different bcc struc tures with very similar lattice parameters. After the second HIP, evidence for $\alpha$ Ti disappeared and the diffraction peaks slightly shifted to positions corresponding to solid solutions with less $\mathrm{Ti}$ content.

The microstructure of the $\mathrm{W}$ 4Ti material after the first and the second HIP is shown in Fig. 4. Pools of Ti(W), which are the black spots surrounded by W grains, were observed uniformly distributed, but no pores were observed. Fig. 4b shows the formation of areas into the Ti pools with a very high $\mathrm{W}$ content after HIP at $1550 \mathrm{~K}$. After the second HIP, the W particles are surrounded by an inter particle $\mathrm{W}$ Ti phase with a Ti content of $\sim 7.2$ wt.\% as Fig. 4d reveals. The sec ond HIP treatment reduced the number and size of these pools and produced a bimodal distribution of grain sizes due to grain growth in the larger Ti pools, as Figs. 4 and 5 illustrate. The effect of the HIP treatments on the cumulative distribution of grain sizes in the Ti pools is shown in Fig. 5 . Despite of the grain growth in the large pools, it should be noted that the average grain size $D_{50}$ did not in crease, see Table 1 . This fact suggests that small Ti(W) grains formed after the second HIP treatment.

\subsection{W Ti $\mathrm{Y}_{2} \mathrm{O}_{3}$ alloys}

Both milled powders, W $2 \mathrm{Ti} 0.47 \mathrm{Y}_{2} \mathrm{O}_{3}$ and $\mathrm{W} 4 \mathrm{Ti} 0.50 \mathrm{Y}_{2} \mathrm{O}_{3}$, rendered fully dense materials after the first HIP treatment. The
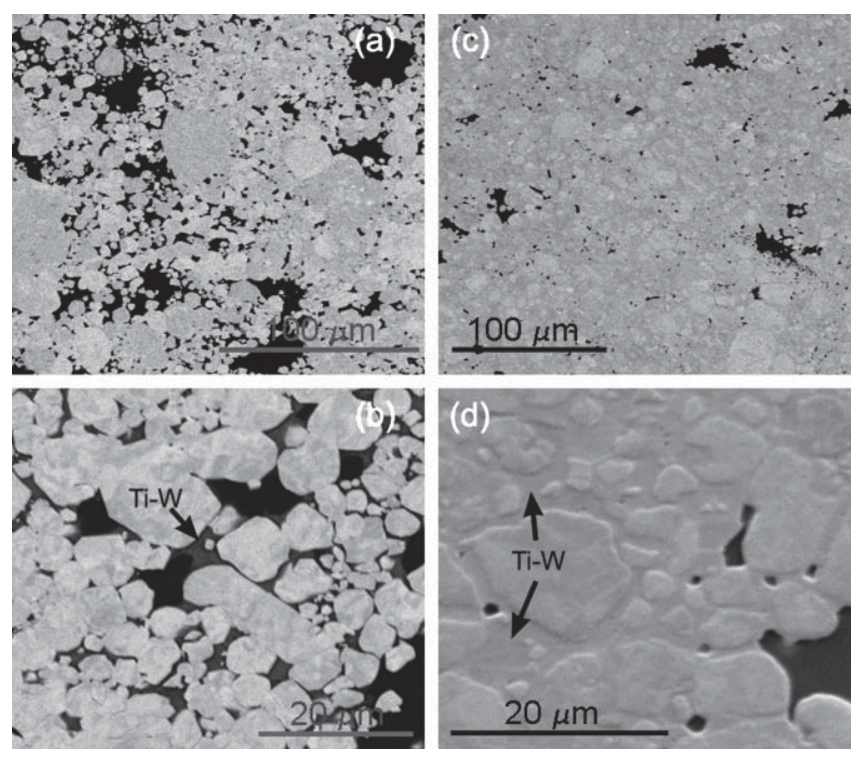

Fig. 4. BSE-SEM images of the W-4Ti material. (a) and (b) after the HIP at $1550 \mathrm{~K}$, (c) and (d) after the second HIP at $1973 \mathrm{~K}$. measured final density was $16.8 \mathrm{~g} / \mathrm{cm}^{3}$ and $16.9 \mathrm{~g} / \mathrm{cm}^{3}$, respec tively. Fig. 6 shows the microstructure of these materials. No pores, and a bimodal distribution of Ti pools similar to that observed in W 4Ti, were also found in these materials after the first HIP treat ment. The distribution of Ti pools in $\mathrm{W} 4 \mathrm{Ti} 0.50 \mathrm{Y}_{2} \mathrm{O}_{3}$ was appar ently equal to the one for $\mathrm{W} 4 \mathrm{Ti}$. The second HIP treatment tended to make round the small Ti pools and reduced the size of the large ones. In the case of $\mathrm{W} 2 \mathrm{Ti} 0.47 \mathrm{Y}_{2} \mathrm{O}_{3}, \mathrm{SEM}$ and EDX anal yses showed a distribution of Ti pools less dense and with a num ber of large Ti pools smaller than the corresponding to $\mathrm{W} 4 \mathrm{Ti} 0.50 \mathrm{Y}_{2} \mathrm{O}_{3}$. The large pools tended to be more elongated than in $\mathrm{W}$ 4Ti $0.50 \mathrm{Y}_{2} \mathrm{O}_{3}$, and the small ones appeared to be outlining the $\mathrm{W}$ particles. The XRD patterns of these alloys exhibited very similar behaviour to that already described for $\mathrm{W} 4 \mathrm{Ti}$, but no $\alpha$ Ti phase in W 2Ti $0.47 \mathrm{Y}_{2} \mathrm{O}_{3}$ was detected after the first HIP at $1550 \mathrm{~K}$. SEM images of $\mathrm{W} 2 \mathrm{Ti} 0.47 \mathrm{Y}_{2} \mathrm{O}_{3} \mathrm{HIP}$ treated at $1550 \mathrm{~K}$ revealed inter particle areas with dark grey contrast, and irregular and diffuse contour, see Fig. 6a. EDX analyses of these areas resulted in compo sitions of W (4 5) wt.\% Ti without any signal of Y or impurities. As in $\mathrm{W} 4 \mathrm{Ti}, \mathrm{W}$ particles were surrounded by a $\mathrm{W}(\mathrm{Ti})$ phase with a $\mathrm{Ti}$ content of $\sim 7 \mathrm{wt} . \%$, as the areas indicated by black arrows in Fig. $6 \mathrm{f}$. EDX analyses revealed that the second HIP at $1973 \mathrm{~K}$ induced the formation of complex oxide aggregates in the previous Ti pools. Ti, $\mathrm{Y}$ and $\mathrm{O}$ in a variable concentration were present in these
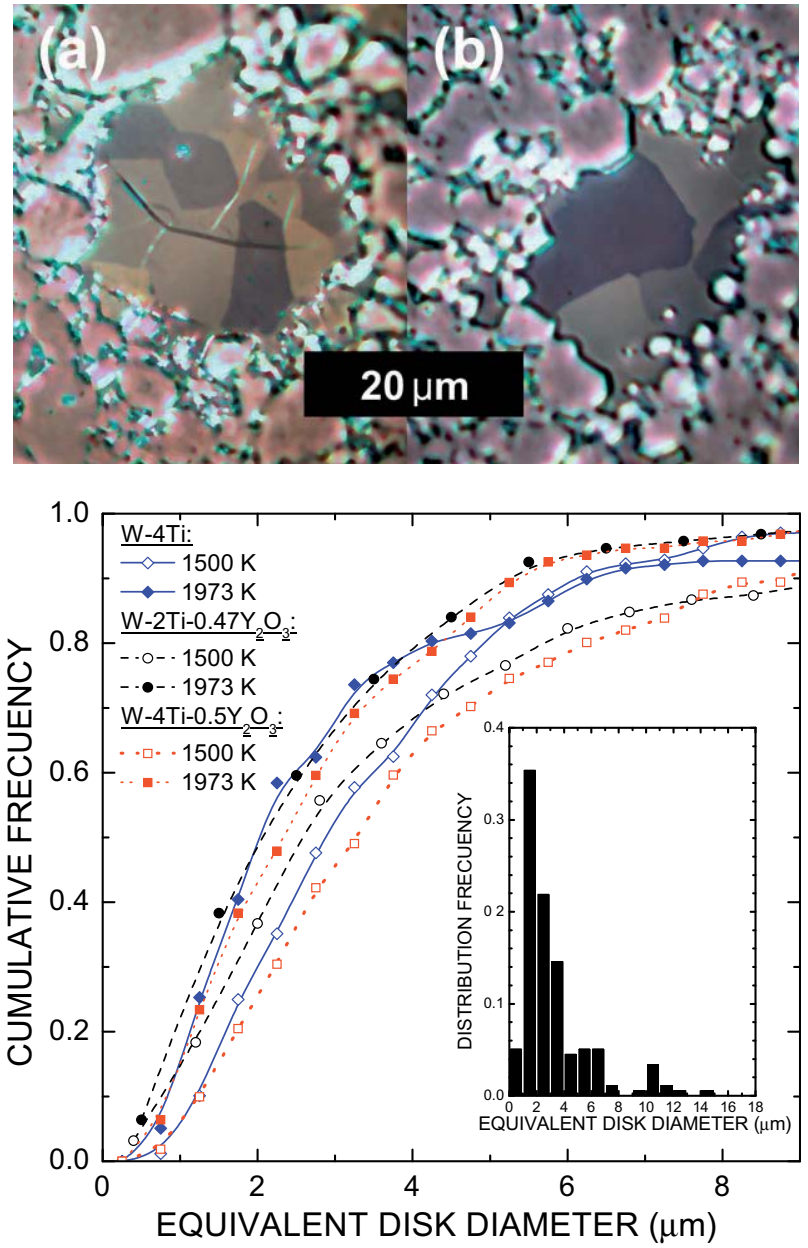

Fig. 5. Micrographs of $\mathrm{W}-4 \mathrm{Ti}$ using crossed polarized light illumination showing the grain growth in the larger Ti pools; after HIP at (a) $1550 \mathrm{~K}$ and (b) $1973 \mathrm{~K}$. The graph depicts the cumulative size distributions of the grains in the Ti pools after the HIP treatments at $1550 \mathrm{~K}$ and $1973 \mathrm{~K}$, for: $(\diamond, \diamond) \mathrm{W}-4 \mathrm{Ti},(\mathrm{O}, \bullet) \mathrm{W}-2 \mathrm{Ti}-0.47 \mathrm{Y}_{2} \mathrm{O}_{3}$ and $\mathrm{W}-2 \mathrm{Ti}-0.50 \mathrm{Y}_{2} \mathrm{O}_{3}(\square, \boldsymbol{\square})$. The inset shows the grain size distribution for $\mathrm{W}-4 \mathrm{Ti}$ after HIP at $1973 \mathrm{~K}$. 
Table 1

Grain size in the $\mathrm{Ti}(\mathrm{W})$ pools corresponding to $50 \%$ of the cumulative size distribution and Vickers microhardness values for the materials successively HIP treated.

\begin{tabular}{|c|c|c|c|c|}
\hline \multirow[t]{2}{*}{ Material } & \multicolumn{2}{|c|}{ Grain size $D_{50}$ for inter-particle $\mathrm{Ti}(\mathrm{W})$ phase } & \multicolumn{2}{|l|}{ Vickers microhardness } \\
\hline & HIP at $1550 \mathrm{~K}(\mu \mathrm{m})$ & HIP at $1973 \mathrm{~K}(\mu \mathrm{m})$ & $\mathrm{HIP} T=1550 \mathrm{~K}(\mathrm{GPa})$ & $\mathrm{HIP} \mathrm{T}=1973 \mathrm{~K}(\mathrm{GPa})$ \\
\hline W & - & - & $2.91 \pm 0.10$ & $2.85 \pm 0.10$ \\
\hline $\mathrm{W}-0.5 \mathrm{Y}_{2} \mathrm{O}_{3}$ & - & - & $2.65 \pm 0.15$ & $2.44 \pm 0.05$ \\
\hline $\mathrm{W}-4 \mathrm{Ti}$ & $2.6 \pm 0.3$ & $2.0 \pm 0.3$ & $4.46 \pm 0.04$ & $4.84 \pm 0.12$ \\
\hline $\mathrm{W}-2 \mathrm{Ti}-0.47 \mathrm{Y}_{2} \mathrm{O}_{3}$ & $2.5 \pm 0.3$ & $1.9 \pm 0.3$ & $4.61 \pm 0.12$ & $3.6 \pm 0.5$ \\
\hline $\mathrm{W}-4 \mathrm{Ti}-0.50 \mathrm{Y}_{2} \mathrm{O}_{3}$ & $3.2 \pm 0.3$ & $1.9 \pm 0.3$ & $6.36 \pm 0.15$ & $4.4 \pm 0.4$ \\
\hline
\end{tabular}
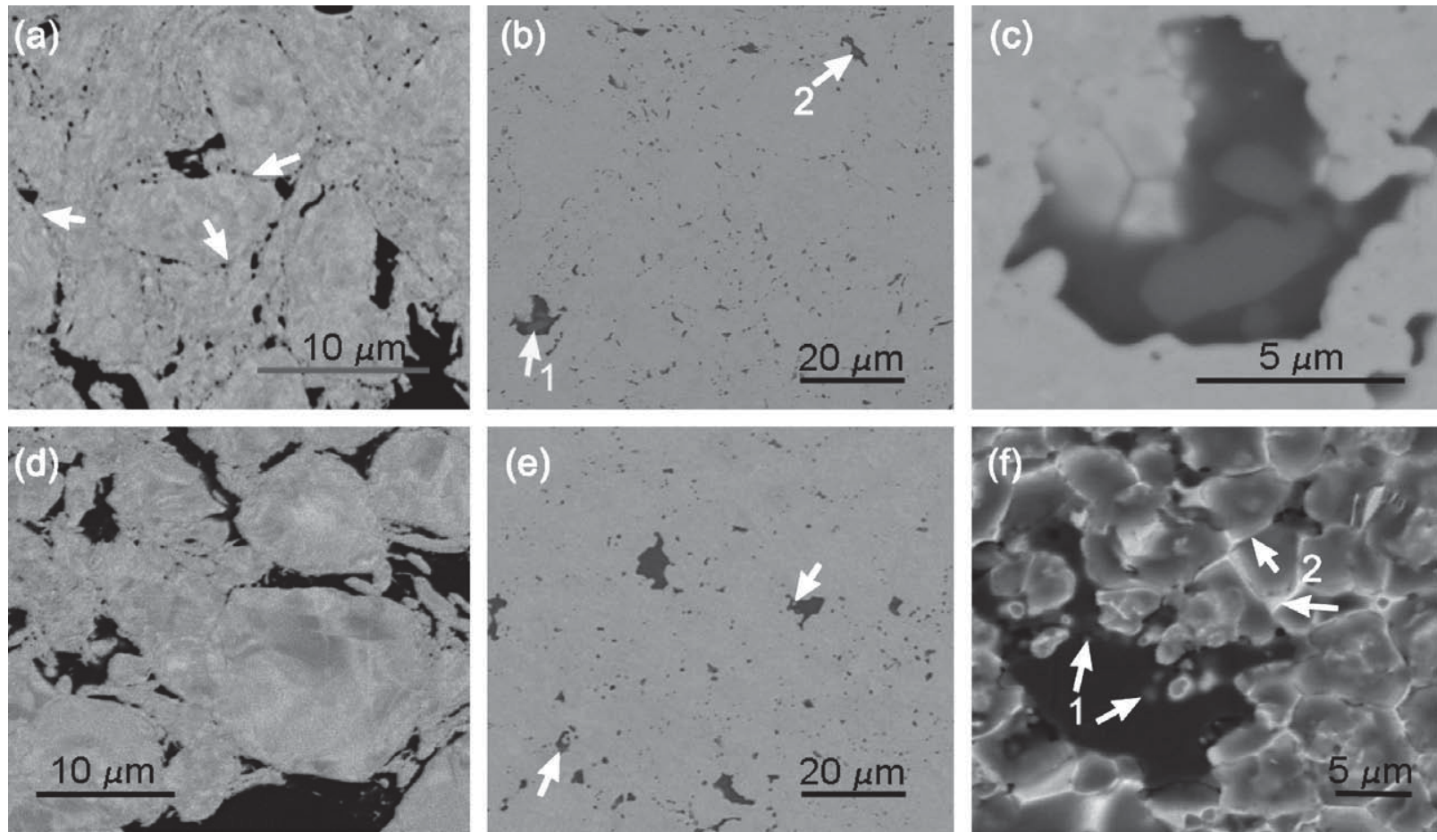

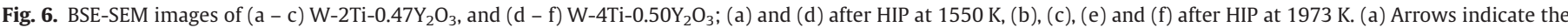
Ti-rich particle boundaries (black contrast). In figures (b), (e) and (f), the arrows indicate new W-Ti-O phases formed after the second HIP treatment (medium grey level contrast).

oxides. The composition and distribution of these oxides appeared to be similar in both materials. Fig. 6c shows a previous Ti pool (black contrast) with several inclusions of the new oxide phase (dark grey contrast) formed after HIP at $1973 \mathrm{~K}$. Similar oxide par ticles were also found inside the previous Ti pools in $\mathrm{W} 4 \mathrm{Ti}$ $0.50 \mathrm{Y}_{2} \mathrm{O}_{3}$, as those indicated by white arrows in Fig. $6 \mathrm{f}$.

The $\beta \mathrm{Ti}(\mathrm{W})$ grains in these alloys exhibited the same behaviour than the one observed for $\mathrm{W} 4 \mathrm{Ti}$, i.e. the second HIP at $1973 \mathrm{~K}$ pro duced a reduction of the average grain size $D_{50}$, see Fig. 5 and Table 1. The grain size distribution of the $\mathrm{W}$ particles was also obtained for both alloys. The average grain sizes $\mathrm{D}_{50}$ resulted in 4.6 and $3.3 \mu \mathrm{m}$ for $\mathrm{W} 2 \mathrm{Ti} 0.47 \mathrm{Y}_{2} \mathrm{O}_{3}$ and $\mathrm{W} 4 \mathrm{Ti} 0.50 \mathrm{Y}_{2} \mathrm{O}_{3}$, respectively.

The TEM analyses performed on W $4 \mathrm{Ti} 0.50 \mathrm{Y}_{2} \mathrm{O}_{3}$ samples HIP treated at $1973 \mathrm{~K}$ also revealed the presence of oxide particles be tween the $\mathrm{W}$ grains, which sizes ranged between 0.5 and $1 \mu \mathrm{m}$. EDX and electron diffraction analyses identified them as complex Ti Y oxides with different compositions and crystalline structure.

\subsection{Microhardness measurements}

Table 1 shows the effect of $\mathrm{Ti}$ and $\mathrm{Y}_{2} \mathrm{O}_{3}$ addition on the microh ardness. 4 wt.\% Ti addition to $\mathrm{W}$ containing $\mathrm{Y}_{2} \mathrm{O}_{3}$ produced microh ardness increments of $\sim 120 \%$ and $80 \%$ in the materials HIP treated at $1550 \mathrm{~K}$ and $1973 \mathrm{~K}$, respectively. $\mathrm{Y}_{2} \mathrm{O}_{3}$ addition to $\mathrm{W}$ reduced the microhardness. The second HIP lowered the microhardness except for $\mathrm{W} 4 \mathrm{Ti}$. This suggests that the formation of the Ti Y oxide phases softened the alloys.

\section{Conclusions}

The HIP treatment at $1973 \mathrm{~K}$ applied to W previously consoli dated by HIP at $1550 \mathrm{~K}$ did not produce further densification be cause of the presence of open porosity in the material. However, addition of $0.5 \mathrm{wt} . \% \mathrm{Y}_{2} \mathrm{O}_{3}$ yielded a material with very low porosity after the second HIP stage at $1973 \mathrm{~K}$. In this case, complex (W Y) oxides were found filling the residual pores.

Addition of 2 or $4 \mathrm{wt} . \% \mathrm{Ti}$ to $\mathrm{W}$ resulted in a fully dense material irrespective of the $\mathrm{Y}_{2} \mathrm{O}_{3}$ presence in the materials $\mathrm{HIP}$ treated at $1550 \mathrm{~K}$. The present results demonstrate that sound $\mathrm{W} \mathrm{Ti} / \mathrm{Y}_{2} \mathrm{O}_{3}$ materials for full mechanical testing can be fabricated by HIP.

The validation of these alloys as PFC materials requires investi gating their mechanical characteristics and behaviour under irradi ation and plasma exposure. The mechanical characterization of these alloys is reported in Ref. [5]. 


\section{Acknowledgments}

The present work was financed by the Dirección General de Investigación (Ministry of Education of Spain, Contract MAT2004 1819), the Dirección General de Universidades (Comunidad de Madrid) through the program of ESTRUMAT CM (Grant S 0505/ MAT/0077) and EURATOM/CIEMAT Association through Contract 07/006.

\section{References}

[1] P. Norajitra et al., J. Nucl. Mater. 329-333 (2004) 1594

[2] G.A. Cottrell, Mat. Sci. Tech. 22 (2006) 869.

[3] H. Bolt, V. Barabash, W. Krauss, J. Linke, R. Neu, S. Suzuki, N. Yoshida, ASDEX Upgrade Team, J. Nucl. Mater. 329-333 (2004) 66

[4] P. Norajitra, A. Gervash, R. Giniyatulin, T. Ihli, W. Krauss, R. Kruessmann, V. Kumetsov, A. Makhankov, I. Mazul, I. Ovchinnikov, Fus. Eng. Des. 81 (2006) 341

[5] J.Y. Pastor, A. Martín, J. Llorca, M.A. Monge, R. Pareja, Proceedings of $13^{\text {th }}$ International Conference on Fusion Reactor Materials Nice, France, 2007, 554. 